\title{
Analisis Periodisitas Gempa Bumi di wilayah Kabupaten Lombok Barat dengan menggunakan Metode Statistik dan Transformasi Wavelet
}

\author{
Fatimatuzzahrah, Lalu A. Didik*, dan Bahtiar \\ Program Studi Tadris Fisika, Fakultas Tarbiyah dan Keguruan, Universitas Islam \\ Negeri Mataram, Jln. Gajah Mada no.100, Jempong Mataram, Kota Mataram 83124
}

Intisari

\begin{abstract}
Penelitian ini bertujuan untuk mengetahui variasi nilai-a (aktivitas seismik) dan nilai-b (tingkat kerapuhan batuan), mengetahui periodesitas gempabumi dengan metode statistik dan transformasi wavelet, dan menganalisis hasil dari metode statistik dan transformasi wavelet diwilayah kabupaten Lombok Barat. Metode yang digunakan untuk menentukan periodesitas gempabumi adalah metode statistik dan transformasi wavelet. Metode statistik dengan prangkat lunak Zmap digunakan untuk menentukan nilai-a, nilai-b, dan periodesitas gempabumi. Pada metode transformasi wavelet digunakan skewness, transformasi Box Cox, dan transformasi wavelet kontinyu untuk menghitung periodesitas gempa. Penelitian ini menggunakan data dari BMKG dan National Earthquake Interntional Center (NEIC) untuk daerah antara episenter $115^{\circ} .46^{\prime}-116^{\circ} .20^{\prime}$ BT, dan $8^{\circ} .25^{\prime}-8^{\circ} .55^{\prime}$ LS dari tanggal 22 Januari 2014 sampai 30 Oktober 2018. Penelitian ini penting dilakukan untuk memberikan analisis kegempaan di Kabupaten Lombok Barat untuk beberapa tahun ke depan. Analisis statistik menghasilkan nilai-a sekitar 5,5-2, nilai-b 0,9-1,8. Kedua parameter tersebut menunjukkan jarangnya terjadi gempabumi dan cukup tingginya stress pada lempeng. Periodisitas berdasarkan hasil analisis statistik adalah sekitar 40-60 tahunan untuk magnitudo 5,5 SR. Dengan metode transformasi wavelet diperoleh periodesitas sebesar 30 tahun dan 60 tahun untuk gempa dengan magnitudo 5,5 SR.
\end{abstract}

\begin{abstract}
This research is experimental research. Where the aim is to find out the first variation of the a- value and the b value, the second is to know the earthquake frequency whit the statistical method and wavelet transformation. And the third to analyze the results of the statistical method and wavelet transformation in the West Lombok regency. The method used to determine the earthquake periodicity in the study is the statistical method and the wavelet transformation. Statistical methods with Zmap software are used to determine a-values, b-values, and earthquake periodicity. The wavelet transformation method uses skewness, Box-Cox transformation, and continue wavelet transformation to calculate earthquake periodicity. This study uses data from BMKG and the National Earthquake International Center (NIEC) for the area between the epicenter of $115^{\circ} .46^{\prime}-116^{\circ} .20^{\prime} \mathrm{BT}$, and $8^{\circ} .25^{\prime}$ to $8^{\circ} .55^{\prime}$ LS from 22 January 2014 to 30 October 2018 . The statistical analysis produces parameters related to seismic conditions (seismic) and tectonic research area. The parameter consists of a value an around 5,5-2 the b-value of 0.9-1.8. Both of these parameters show a rare earthquake and quite high stress on the plate. Periodicity based on the results of statistical analysis is around 40-60 years for magnitude 5.5 SR. with the wavelet transformation method, the periodicity of 30 years and 60 years is obtained for earthquakes with magnitude 5.5 SR. these results indicate that the two methods produce almost the same periodicity values.
\end{abstract}

Keywords: Earthquake Periodecity; Statistics and Wavelet Transformation.

*Corresponding author: laludidik@uinmataram.ac.id

http://dx.doi.org/10.12962/j24604682.v16i1.5717

2460-4682 @Departemen Fisika, FSAD-ITS

\section{PENDAHULUAN}

Indonesia adalah salah satu negara didunia yang mempunyai wilayah yang tektoniknya sangat aktif. Kepulauan Indonesia secara geografis diapit oleh dua benua dan dua samudra, yakni benua Eropa dan Australia serta Samudera Hinda dan Samudera Pasifik. Indonesia termasuk golongan negara yang dekat dengan batas lempeng tektonik Eurasia dan IndoAustralia, Lempeng Indo-Australia merupakan lempengan yang menunjam ke bawah lempeng Eurasia, di bagia timur bertemu tiga lempeng tektonik, yaitu lempeng Filipina, Pasifik, dan Indo-Australia, bertemunya lempeng Indo-Australia dan lempeng Eurasia menyebabkan terbentuknya deretan gunung berapi, diantaranya bukit barisan dipulau Sumatra dan di sepanjang pulau Jawa, Bali, dan Lombok [1]. 
Lempengan di Indonesia yang terus bergerak mengakibatkan benturan yang cukup keras, mengakibatkan wilayah Indonesia dikatagorikan sebagai wilayah yang aktivitas kegunung-apian dan kegempaanya relatif tinggi. Oleh karena itu, Indonesia dikatakan negara yang rentan terhadap bencana alam (natural disaster), karena ulah manusia itu sendiri (manmade disaster). Salah satu pulau di Indonesia, yaitu Nusa Tenggara Barat khususnya di Lombok termasuk titik rawan bencana gempa, karena Lombok merupakan kawasan sesar seismik aktif, dan berada diantara dua pembangkit gempa yaitu selatan dan utara. Pada posisi selatan terdapat zona subduksi Lempeng Indo-Australia yang menunjam ke bawah, sedangkan dari Utara terdapat struktur geologi sesar Naik Flores atau disebut Flores Back Arc Thrusting [2].

Gempabumi yang terjadi pada 29 Juli-30 Agustus 2018 lalu telah memakan korban, berdasarkan data BNPB yang dikutip dari kompas.com (1/10/2018) menyatakan bahwa jumlah korban jiwa yang meninggal dunia sebanyak 564 orang dengan rincian, yaitu Kabupaten Lombok Utara sebanyak 467 orang, Kabupaten Lombok Barat sebanyak 44 orang, dan Kabupaten Lombok Timur sebanyak 31 orang. Rumah rusak mencapai 73.843 unit dan 798 fasilitas umum dan sosial mengalami kerusakan akibat gempa. Kerugian tersebut disebabkan oleh rendahnya penanganan pemerintah daerah maupun pusat terhadap masyarakat seperti sosialisasi tentang gempa sejak dini, penyebaran peta rawan gempa disetiap daerah masih sangat minim, dan kurangnya metode tindak lanjut dalam hal mitigasi bencana gempa pada masyarakat [3]. Ancaman bencana di Kab. Lombok Barat berdasarkan Indeks Rawan Bencana tahun 2011 yang diterbitkan oleh BNPB adalah banjir, gempabumi, tsunami, kebakaran permukiman, kekeringan, cuaca ekstrem, longsor, gunung-api, abrasi, konflik sosial, epidemi, dan wabah penyakit.

Terjadinya gempabumi disebabkan oleh suatu gerakan atau hentakan tiba-tiba akibat pelepasan akumulasi energi yang disebabkan oleh tumbukan antar lempeng, pergeseran sesar, aktivitas gunung api atau proses-proses lain hasil dari pelepasan akumulasi energi di bumi. Energi yang terlepas tersebut disebarkan ke segala arah dalam bentuk gelombang seismik atau gelombang gempa [4].

Sesuai dengan ilustrasi geoposisi dan geologi, kawasan Kabupaten Lombok Barat memiliki memiliki potensi yang sama dengan wilayah lain yang ada di pulau Lombok. Kabupaten Lombok Barat didukung dengan adanya potensi kerawanan gempabumi tektonik. Kawasan yang berada di lepas pantai selatan dan barat dari kabupaten Lombok Barat adalah daerah yang memiliki potensi sebagai episenter di laut, sehingga kemungkinan bisa berpotensi tsunami.

Berdasarkan penelusuran lapangan, gempa kecil maupun besar sering terjadi di wilayah Kabupaten Lombok Barat. Dari data BMKG (Badan Meteorologi Klimatologi dan Geofisika) gempa yang ikut melanda Kabupaten Lombok Barat pada 29 Juli-30 Agustus 2018 bulan lalu yang berkekuatan 7,0 SR paling besar dibandingkan tahun sebelumnya pada 23 Juni 2013 pukul 13:42 Wita dengan kedalaman $10 \mathrm{~km}$ dan kekuatan 5,4 Mw, ini menandakan bahwa mempunyai tingkatan stress yang tinggi, mengakibatkan banyak memakan korban jiwa dan kerugian pada saat itu. Hal ini disebakan

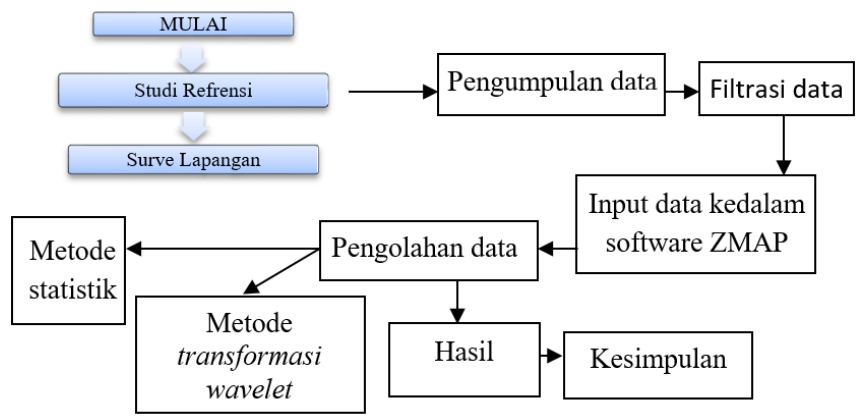

Gambar 1: Desain Penelitian.

karena kurangnya metode yang digunakan untuk menanggulangi atau menganalisis gempabumi yang telah terjadi. Periodisitas gempabumi ini merupakan periode ulang gempabumi yang diperoleh dengan mengetahui nilai parameter keaktifan gempabumi dengan keadaan seismitas dan keadaan tektonik, manfaat yang didapatkan yaitu: untuk mengetahui variansi nilai nilai-b dalam mengamati tingkat kerapuhan batuan serta nilai-a tingkat seismisitas yang besarnya tergantung pada periode gempa yang rendah sebelum terjadinya gempa kuat [5].

Menurut Rikitake dan Hagiwara yang menganggap bahwa gempabumi sebagai suatu proses yang diperbaharui, yang mana akumulasi energi strain elastik diperbaharui dalam periode yang panjang setelah terjadinya sebuah gempabumi sebelum terjadi gempabumi berikutnya. Pendekatan ini untuk prediksi gempabumi telah banyak diaplikasikan sebagai dasar untuk prediksi jangka panjang dari aktivitas kegempaan di waktu yang akan datang. Model prediksi dengan metode wavelet mampu mendeteksi adanya kecenderungan kenaikan aktivitas gempabumi sebelum gempa besar. Metode prediksi ini sangat bergantung pada katalog dan kualitas katalog dalam mencatat gempa yang terjadi [6].

Penelitian ini bertujuan untuk mengetahui variansi nilai-a dan nilai-b wilayah Kabupaten Lombok Barat, mengetahui periodisitas gempabumi yang diukur dengan metode statistik dan transformasi wavelet di wilayah Kabupaten Lombok Barat, dan menganalisis hasil dari metode statistik dan transformasi wavelet dalam menentukan periodesitas gempabumi.

\section{METODE PENELITIAN}

Desain yang digunakan dalam penelitian ini dapat dijelaskan secara lebih ringkas pada Gambar 1. Penelitian ini akan dilaksanakan pada tanggal 10 Maret 2019 di Pusat Penelitian dan Pengembangan (Publitbang) BMKG di Selaparang. Data yang didapatkan berupa data magnitudo, dan metode penelitian yang digunakan adalah metode statistik dan transormasi wavelet untuk mendapatkan variansi nilai-a (aktivitas seismik), nilai-b (karakteristik tekanan yang dialami oleh medium), menganalisis hasil dari metode statistik dan transformasi wavelet dalam menentukan periodesitas gempabumi di wilayah Kabupaten Lombok Barat.

Dalam penelitian ini, dilakukan pengambilan data di BMKG yang ada di Selaparang. Pengambilan data dilakukan 


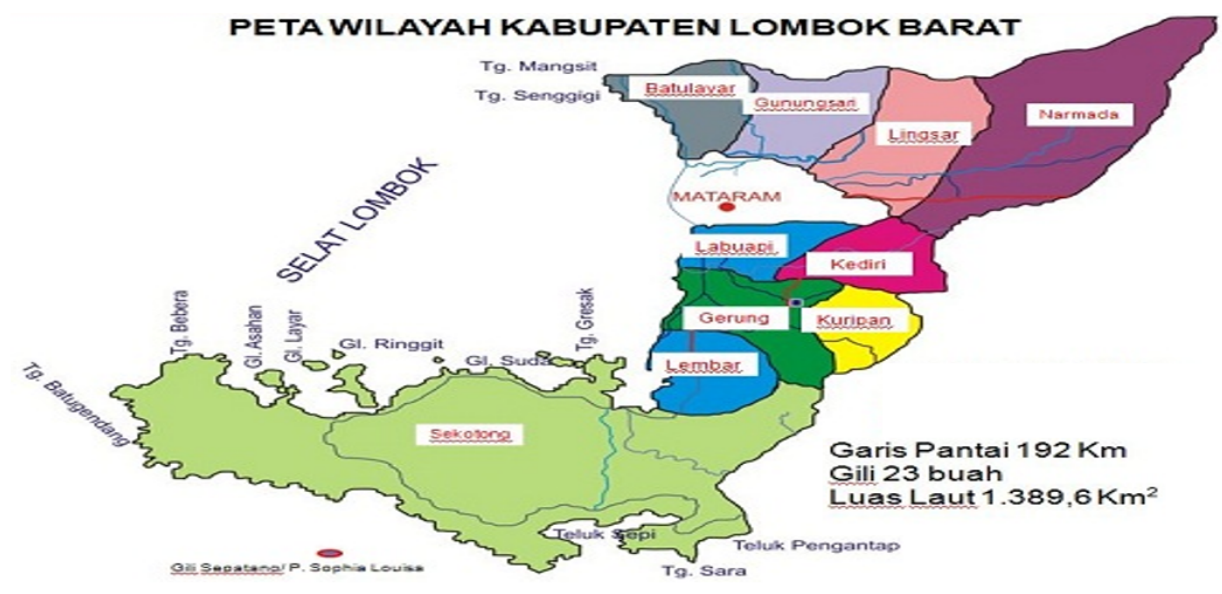

Gambar 2: Peta Wilayah Kabupaten Lombok Barat.

selama dua hari terhitung dari tanggal 10 sampai 11 Maret 2019. Hari pertama yaitu konsultasi dengan pihak BMKG mengenai proses pengambilan data yang dimiliki oleh BMKG dan hari kedua yaitu peroses transfer data yang dimiliki BMKG yang dikomparasi dengan data NEIC kepada peneliti. Data yang diperoleh dari BMKG berupa waktu, episenter, letak geografis dan magnitude gempa yang terjadi di wilayah Kabupaten Lombok Barat dari 22 Januari 2014 sampai 31 Oktober 2018.

Gambar 2 menunjukkan peta wilayah kabupaten Lombok Barat. Kabupaten Lombok Barat terletak di atara $115^{\circ} .46^{\prime}-$ $116^{\circ} .20^{\prime}$ BT dan $8^{\circ} .25^{\prime}-8^{\circ} .55^{\prime}$ LS, dengan batas wilyah disebelah barat dengan selat Lombok dan kota Mataram; sebelah timur berbatasan dengan kab. Lombok Tengah; sebelah utara berbatasan dengan kabupaten Lombok Utara, dan Sebelah selatan berbatasan dengan Samudra Hindia [7].

Metode statistik sebagai disiplin ilmu dengan formula empirik dari Gutenberg and Richter. Sampai saat ini belum ada metode yang mampu menandingi keakuratan dari formula empiris tersebut terkait kemampuannya dalam menjelaskan masalah sesismisitas dengan lebih baik [8]. Metode ini telah digunakan secara luas dan telah teruji secara meyakinkan keakuratannya. Secara matematis formula tersebut dapat dituliskan:

$$
\log N=a-b M
$$

dengan $\mathrm{N}$ adalah jumlah gempabumi, $\mathrm{M}$ adalah magnitudo gempabumi, $a$ dan $b$ adalah konstanta real yang bernilai positif. Konstanta $a$ menggambarkan aktivitas seismik dan $b$ menggambarkan karakteristik tekanan yang dialami oleh medium medium. Formula empirik dari Gutenberg and Richter tersebut dapat menjelaskan dengan baik terkait sesismisitas gempabumi dengan magnitudo antara 4,5 sampai dengan 7,0, Sedangkan untuk gempabumi dengan magnitudo di atas 7,0 formula tersebut perlu dimodifikasi karena kemungkinan besar terjadi deviasi linieritas, dengan nilai log $\mathrm{N}$ cenderung tidak linier terhadap M. Jumlah gempabumi dengan $\mathbf{M}$ lebih besar dari 7,0 sedikit, jumlah $\mathrm{N}$ cenderung kecil untuk $\mathrm{M}$ besar $(>7,0)$. Oleh karena itu perlu dimasukkan faktor magnitudo momen $(\mathrm{Mw})$ [9].

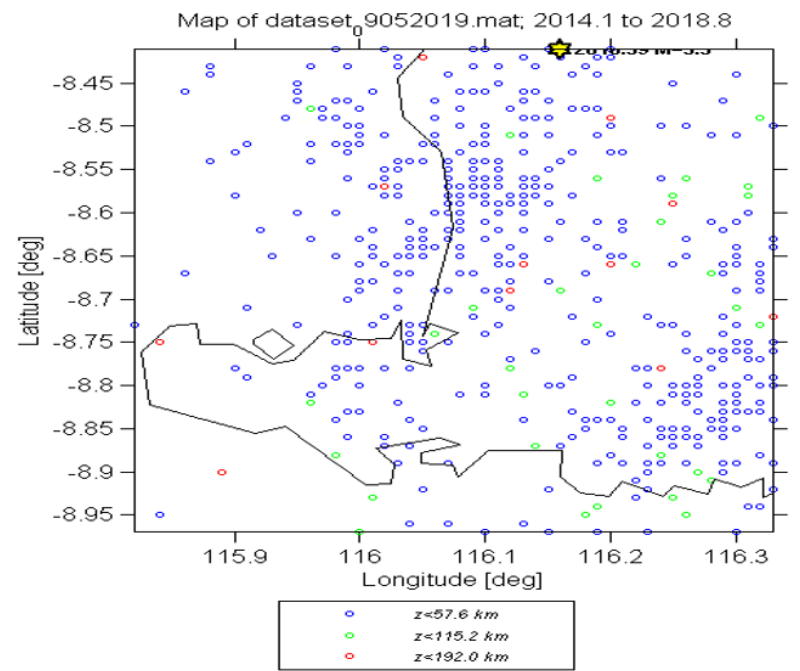

Gambar 3: Peta seismisitas wilayah Kabupaten Lombok Barat berdasarkan katalog NEIC dan BMKG (simbol O menyatakan satu kejadiangempa dan warnanya menentukan kedalamannya, * gempa dengan magnitudo 5,5 SR).

\section{HASIL DAN DISKUSI}

Pengolahan data pada wilayah Kabupaten Lombok Barat dari 22 Januari 2014 sampai 31 Oktober 2018 dengan menggunakan metode statistik memperoleh peta variansi nilai-a dan nilai-b serta periodesitas gempabumi di wilayah Kabupaten Lombok Barat pada magnitudo 5,5 Mw. Dengan menggunakan metode statistik juga dapat diperoleh peta seismisitas seperti pada Gambar 3 serta histogram magnitudo dengan jumlah gempa pada Gambar 4.

Pada peta seismisitas (Gambar 3) dan histogram (Gambar 4) menunjukkan bahwa wilayah kabupaten Lombok Barat yang sering terjadi gempabumi. Kejadian gempabumi dengan magnitudo 3 SR hampir sekitar 20-60 kali kejadian selama periode penelitian yang ditunjukkan pada Gambar 4. Pada 


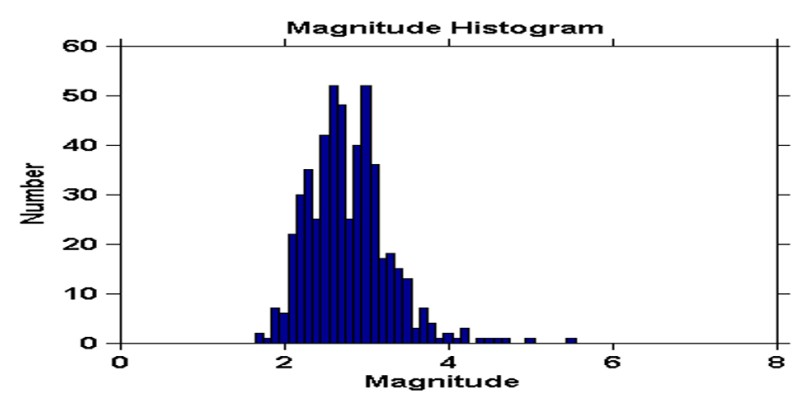

Gambar 4: Histogram hubungan magnitudo dengan jumlah kejadian gempa menggunakan data dari katalog NEIC dan BMKG.

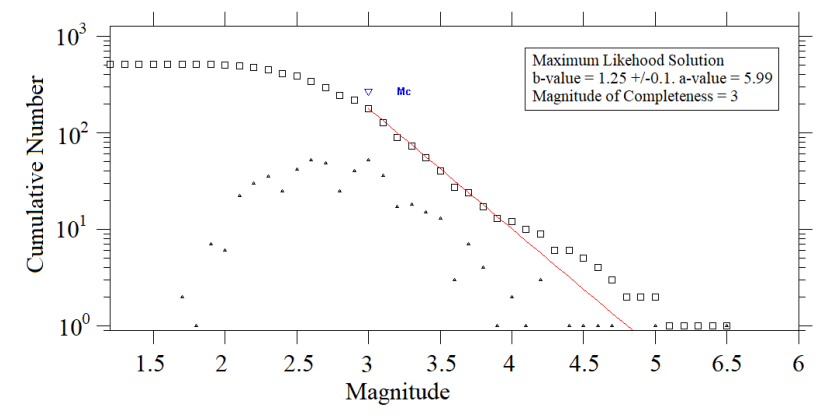

Gambar 5: Distribusi frekuensi magnitudo dengan data katalog NEIC dan BMKG $(\triangle=$ gempabumi berdasarkan catalog, dan $\square$ = gempabumi hasil perhitungan dengan metode maximum likelihood).

wilayah ini sering terjadi gempabumi karena daerah subdiksi Lempeng Indo-Australia dan struktur geologi sesar Naik Flores atau disebut Flores Back Arc Thrusting dengan kedalaman $57,5 \mathrm{~km}$

Dari peta seismisitas, gempabumi diwilayah kabupaten Lombok Barat menunjukkan bahwa gempa paling besar yang terjadi pada tahun 2018 dengan magnitudo 5,5 SR yang mengakibatkan banyak rumah yang rusak dan memakan korban pada saat itu.

Berdasarkan Gambar 3 dan Gambar 4 dapat diperlihatkan bahwa wilayah ini jarang terjadi gempabumi, namun sering merasakan gempa yang berpusat disekitaran Nusa Tenggara Barat (NTB) dan diluar pulau Nusa Tenggara Barat (NTB) dengan magnitudo 5SR-7SR. Untuk mengetahui variansi nilaia dan variansi nilai-b di wilayah kabupaten Lombok Barat perlu diketahui nilai magnitudo of complitness (Mc) yang dapat diperoleh melalui Gambar 5.

Pada Gambar 6 menunjukkan bahwa hubungan magnitudo dengan jumlah gempa rendah. Dari grafik hubungan tersebut diperoleh nilai magnitudo of complerness $(\mathrm{Mc})=3$ yang ditandai dengan segitiga biru pada gambar, nilaib $=1,25$ dengan standar error 0,1 , dan nilai-a $=5,99$. Sehingga perhitungan nilai-a, nilai -b dan nilai Mc secara keseluruhan dapat diperoleh melalui perhitungan dengan menggunakan metode maximum likelihood. Dapat dilihat nilai-a yang tinggi yaitu 5,99 , sehingga pada wilayah ini memiliki tingkat aktifitas seis-

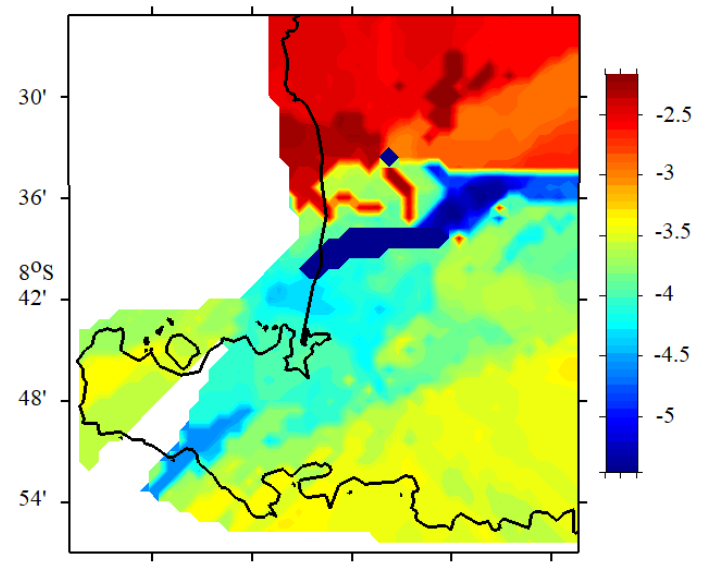

Gambar 6: Variasi spasial nilaia wilayah kabupaten Lombok Barat dengan data yang ada pada katalog NEIC dan BMKG, dimana nilaia ditentukan dengan grid $0,10 \times 0,10$.

miknya rendah. Nilai-b tergantung dari sifat batuan setempat serta tingkat kerapuhan batuannya. Makin rendah nilai-b menyatakan tingkat stress yang tinggi pada wilayah penelitian, serta nilai Mc yang digunakan untuk memodelkan data yang hilang dari katalog sehingga pada nilai Mc sangat diperlukan nilai-a dan nilai-b [10]. makin besar nilai-a di suatu daerah, maka daerah tersebut memiliki aktivitas seismik yang semakin tinggi dan semakin redah nilai-a maka semakin rendah pula aktifitas seismik, begitu pun dalam penelitian Bambang Sunardi, menyatakan bahwa semakin besar nilai-a di suatu daerah maka, daerah tersebut memiliki aktivitas seismik semakin tiggi, sebaliknya daerah yang memiliki nilai-a yang relatif rendah, aktivitas seismiknya akan relatif lebih rendah [11].

Salah satu parameter yang paling penting dalam menentukan nilai-b dan nilai-a adalah Magnitude Completenes (Mc) dimana diperlukan deskripsi yang akurat dari Mc lokalnya, karena pada wilayah penelitian sangat bervariasi harus diperhatiakan Mc untuk menjelaskan bahwa magnitudo minimum terbaik untuk memulai perhitungan nilai-b setiap katalog tersebut [12]. Berdasarkan nilai-a dan nilai-b dari peta densitas di wilayah kabupaten Lombok Barat dapat diperhatikan pada Gambar 6, Gambar 7, dan Gambar 8.

Dari Gambar 6 dan Gambar 7 dapat dilihat daerah wilayah Kabupaten Lombok Barat yang memiliki nilai-a dan nilai-b yang rendah, sedang maupun tinggi berdasarkan warna pada gambar di atas. Berdasarkan relasi Gutenberg-Richter, nilai-a merupakan parameter seismik, diamana jika nilai-a semakin besar maka aktivitas kegempaannya semakin sering dan semakin kecil nilaia maka aktivitas kegempaannya semakin jarang terjadi. Nilai-b merupakan parameter tektonik, menurut para ahli ketika nilai-b rendah biasanya berkorelasi dengan tingkat stress lempeng yang tinggi dan ketika nilaib tinggi maka berkorelasi dengan tingkat stress lempeng yang rendah [13].

Berdasarkan hasil pengolahan data, dari peta variasi spasial nilaia dan nilaib dari katalog NEIC dan BMKG sejak 22 Januari 2014 sampai 31 Oktober 2018 terlihat variasi nilai-a berk- 


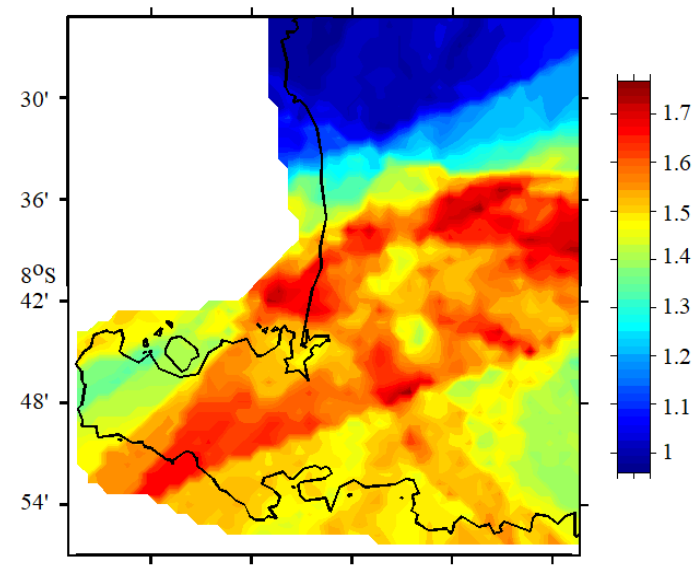

Gambar 7: Variasi spasial nilaib di wilayah kabupaten

Lombok Barat dengan katalog NEIC dan BMKG menggunakan parameter yang sama dengan penentuan nilaia.

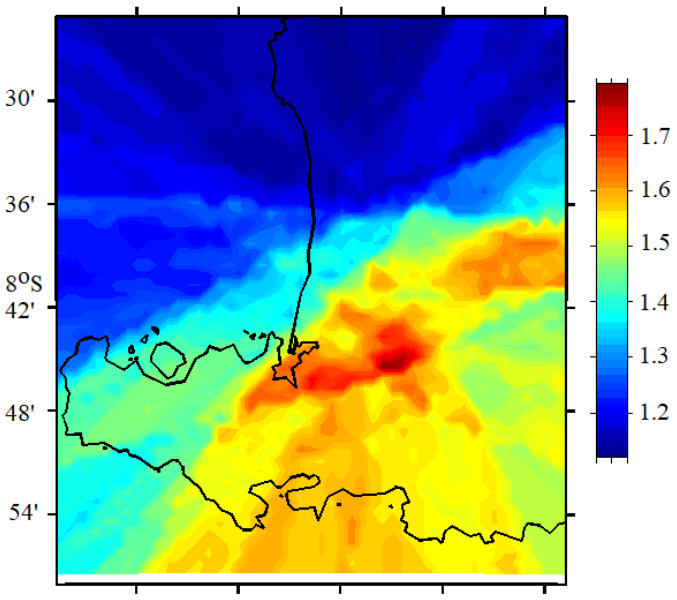

Gambar 8: variasi densitas gempabumi wilayah kabupaten Lombok Barat dengan katalog NEIC dan BMKG menggunakan parameter yang sama dengan penentuan nilai-a.

isaran dari 4-26 dan variasi nilai-b berkisaran dari 0,9-1,8 dominan di wilayah kabupaten Lombok Barat.

Berdasarkan peta densitas kegempaan seperti Gambar 8 wilayah kabupaten Lombok Barat memiliki variasi berkisaran antara $-1 \mathrm{~s} / \mathrm{d}$ 0,1 - $\log \left(\mathrm{EQ} / \mathrm{km}^{2}\right)$ dengan EQ adalah jumlah gempa. Nilai desitas masing-masing wilayah ditunjukkan oleh perbedaan warna pada gambar. Wilayah yang berwarna merah memiliki tingkat kerapatan gempa yang relatif lebih tinggi dibandingkan dengan wilayah lainnya. Tingkat kerapatan yang tinggi berarti daerah tersebut sering terjadi gempa, semakin tinggi nilai densitas maka semakin tinggi tingkat kegempaan dan semakin rendah nilai densitas maka semakin rendah tingkat kegempaan pada wilayah tersebut.

Dengan menggunakan persamaan Skweness diperoleh periodesitas gempabumi wilayah kabupaten Lombok Barat dengan gempabumi 5,5 SR pada Gambar 9 berkisaran antara

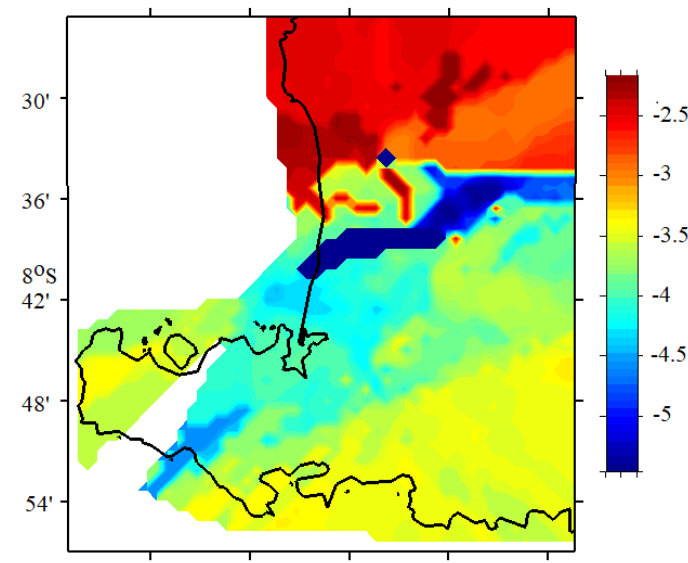

Gambar 9: Periodisitas gempabumi $\mathrm{M}=5 \mathrm{SR}$ wilayah Kabupaten Lombok Barat dengan data katalog NEIC dan BMKG menggunakan parameter yang sama dengan penentuan nilai-a.

40-60 tahunan ditandai dengan warna coklat yang terjadi di sekitar kabupaten Lombok barat.

\section{Periodisitas gempabumi dengan metode transformasi wavelet.}

Dalam pengolahan data dari periodesitas gempabumi dengan transformasi wavelet, penentuan periodesitas kegempaan ini dibedakan berdasarkan densitas, nilai-a dan nilai-b dari pengolahan data dari metode statistik.

Periodisitas gempabumi dengan menggunakan metode transformasi wavelet berlaku untuk gempabumi dengan magnitudo kurang dari 6. Dimana prinsip periode ulang gempabumi yaitu gempa dengan magnitudo relatif besar memiliki periode ulang yang relatif lama, sehingga untuk memperoleh hasil periodesitas gempabumi yang akurat dibutuhkan katalog gempabumi yang lebih panjang. Pada analisis periodesitas gempabumi dengan metode transformasi wavelet ini, periodesitas yang diperoleh dan dapat ditentukan kurang dari setengah panjang katalog [14].

Pada penelitian ini menggunakan metode transformasi wavelet, digunakan bantuan metode statistik yaitu transformasi Box Cox yang berguna untuk menormalkan data energi yang diperoleh. Dalam membantu menormalkan data ini, diperlukan nilai variabel $\lambda$. Nilai $\lambda$ diperoleh dari hasil nilai skewness mendekati nol dan menggunakan bantuan plot hubungan nilai $\lambda$ pada sumbu $\mathrm{x}$ dan nilai skewness-nya pada sumbu y. Dengan data yang sudah terdistribusi normal ini dapat diperoleh periodesitas gempabumi wilayah kabupaten Lombok Barat seperti diperlihatkan pada Gambar 10.

Pada Gambar 10(a) dari data energi yang dilepas oleh gempa-gempa yang terjadi diwilayah penelitian, tampak tidak adanya menunjukkan adanya periodesitas tertentu. Pada Gambar 10(b) terlihat nilai spektrum daya terbesar sekitar 30 tahun dan 60 tahun. Jika dibandingkan antara periodesitas berdasarkan statistik kegempaan dengan periodesitas dominan menggunakan metode wavelet terlihat satu kesamaan waktu perulangan gempa skitar 40-60 tahun. Periodisitas 


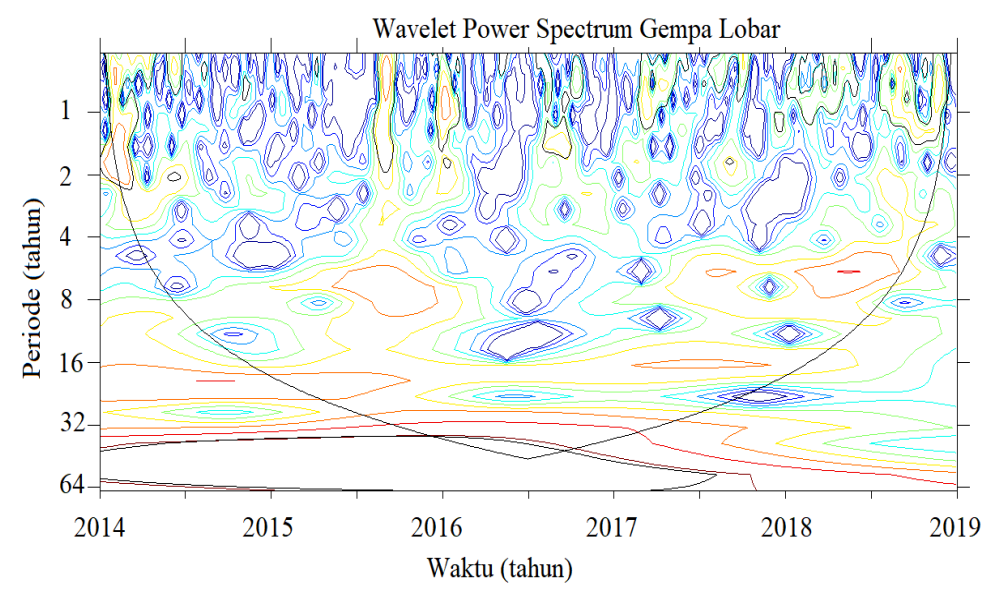

(a)

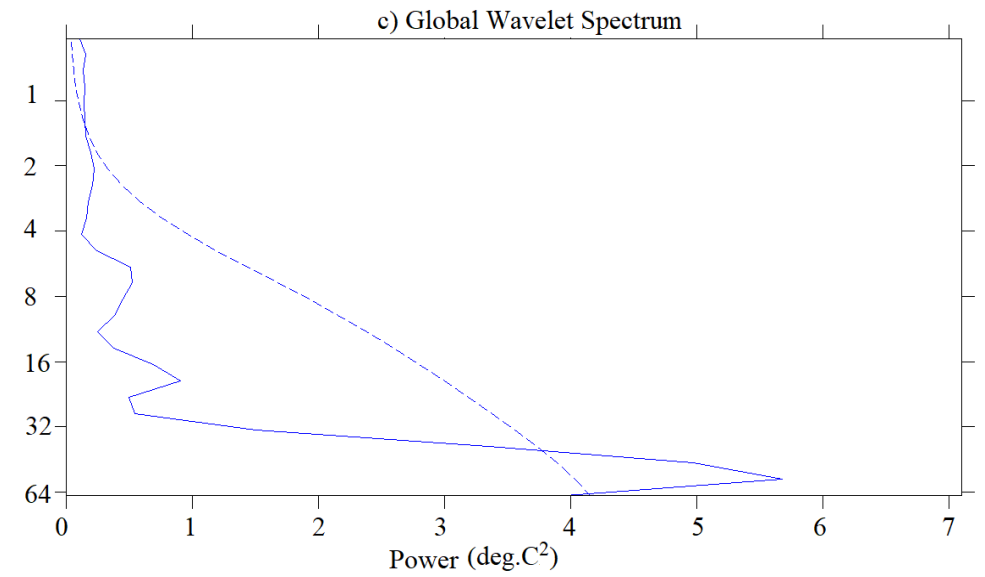

(b)

Gambar 10: Plot spektrum daya wavelet gempabumi wilayah kabupaten Lombok Barat dengan N= 60 dan garis lengkung adalah batas efek tepi. Gambar (a) sama dengan gambar (b), tetapi hanya menggambarkan spektrum Fourier dan spektrum global.

dominan pada statistik kegempaan wilayah kabupaten Lombok Barat, ditandai dengan warna biru.

Dari gambar plot koefisien wavelet, Gambar 10(a) sumbu horizontal menunjukkan waktu (tahun), dan sumbu vertikal menunjukkan periodesitas. Pada Gambar 10(b) menunjukkan periode dengan cara yang berbeda, dimana sumbu horizontal menunjukkan spektrum daya Fourier dan sumbu vertikal menunjukkan skala periodesitasnya.

Periodisitas gempabumi yang diperoleh dengan metode transformasi wavelet dan metode statistik hampir sama, namun dengan metode transformasi wavelet lebih teliti dibandingkan metode statistik. Pada metode statistik digunakan perkiraan perhitungan rata-rata maksimum dari kejadian gempabumi. Sedangkan pada metode transformasi wavelet informasi yang diperoleh lebih detail dan menyeluruh karena adanya faktor skala sinyal frekuensi. Dimana skala besar (frekuensi rendah) menyebabkan sinyal menjadi besar dan dapat digunakan untuk mengetahui informasi detail yang ada dalam sinyal, saat skala kecil (frekuensi tinggi) dapat mengetahui secara menyeluruh [15].

\section{SIMPULAN}

Berdasarkan hasil pengolahan data gempabumi di wilayah kabupaten Lombok Barat yang terletak antara $115^{\circ} .46^{\prime}$ $116^{\circ} .20^{\prime}$ BT dan $8^{\circ} .25^{\prime}-8^{\circ} .55^{\prime}$ LS dengan metode statistik diperoleh simpulan bahwa:

- Variasi nilai-a wilayah kabupaten Lombok Barat relatif tinggi yaitu (-4)-(-25) dan nilai-b berkisaran 0,9-1,8. Semakin tinggi nilai-a maka aktivitas kegempaan semakin tinggi begitu pula sebaliknya, dan semakin tinggi variasi nilai-b maka tingkat stress lempeng semakin rendah begitu pula sebaliknya.

- Periodisitas kegempaan berdasarkan metode statistik diperoleh pada magnitude 5,5 SR domian sekitar 40-60 
tahun dan periodesitas kegempaan dengan metode transformasi wavelet di wilayah kabupaten Lombok Barat dominan 30-60 tahun.

- Hasil pengolahan periodesitas gempabumi dengan metode statistik hampir sama dengan periodisitas gempabumi dengan metode transformasi wavelet. Informasi yang diperoleh dari kedua metode ini saling melengkapi, namun hasil yang diperoleh melalui metode transformasi wavelet lebih teliti karena rentang waktu periodisitas gempa yang lebih besar.

\section{Ucapan Terima Kasih}

Terima kasih kepada kepala BMKG stasiun Geofisika Mataram yang telah memberikan izin peneliti untuk melakukan penelitian. Terima kasih juga kepada Tim Laboratorium Fisika UIN Mataram yang telah membantu peneliti dalam menganalisis data.
[1] P.R. Riani, "Analisis Data Geomagnet Menggunakan Metode Polarisasi", Dielektrika, vol. 3, no. 1, hlm. 75-84, 2016.

[2] D.S. Agustawijaya, "The Development Of Hazard Riska Nalysis Method: A case Study In Lombok Island”, Dinamika Teknik Sipil, 12 (2), hlm. 146-150, 2009.

[3] http://Compas.com, Kamis, 7 Juli 2019, jam 12;54 Wita.

[4] T. Rahmad, D. Sugianto, "Kajian Seismisitas Dan Periode Ulang Gempa Bumi Di Aceh", Jurnal Ilmu Kebencanaan (JIKA), vol. 2, no. 1, hlm. 44-50, 2015.

[5] N. Fransiska, "Penentuan Prekursor Gempa Bumi Menggunakan Data”, Youngster Physics Journal, vol. 1, no. 4, 115-120, 2013.

[6] L. Royani, "Studi Tentang Estimasi Awal Terjadinya Gempa Bumi Menggunakan Metode B-Value Dan Z-Value", Jurnal Inovasi Fisika Indonesia (IFI), vol. 06, hlm. 97-103, 2017.

[7] S. Rahadi, "Magnitude Tertentu Berdasarkan Model Guttenberg - Ritcher", Spektra, vol. 15, no. 1, 44-48, 2014.

[8] BMKG Stasiun Klimatologi Kelas I Lombok Barat, Jumat, 08 November 2018, jam 10:25.

[9] A.A. Mulya, "Statistika Penelitian", Insan Madani Publishing Mataram, Mataram, hlm. 2-3, 2016.

[10] Madlazim, "Kajian Awal Tentang b Vuale Gempa Bumi di Sumatra Tahun 1964-2013”, Jurnal Penelitian Fisika dan Ap- likasinya (JPFA), vol. 3, no. 1, hlm. 43, 2013

[11] W. Asnita, D. Sugiyanto, I. Rusydy, dan Madlazim, "Kajian Statistik Seismisitas Kawasan Sumatera", Natural, vol. 16, no. 2, hlm. 11-12, 2016

[12] B. Sunardi, B. (2017). "Analisis Seismotektonik Dan Periode Ulang Gempabumi Wilayah Nusa Analisis Seismotektonik Dan Periode Ulang Gempabumi Wilayah Nusa Tenggara Barat, Tahun 1973-2015”, Riset Geo Indonesia, 2017. [ https://www.academia.edu/33021958/Analisis Seismotektonik dan Periode Ulang Gempabumi Wilayah Nusa Tenggara Barat Tahun 1973-2015]

[13] I. Ramadhani, dan B.J. Santosa, "Relokasi Hypocentre Gempa Bumi Velest (JHD) Estimasi Sesar Daerah Sumatra Selatan”, J. Fis. dan Apl., vol. 13, no. 2, hlm. 63-73, 2017.

[14] S. Rahayu, "Analisis Periodesitas Gempa Bumi Di Wilayah Nusa Tenggara Dan Sekitarnya Dengan Metode Statistik Dan Transformasi Wavelet", Skripsi Universitas Mataram. 050, 2011.

[15] D. Alam, dan Sumainna, "Kompresi Citra Berwarna Menggunakan Transformasi Wavelet", Matematika Integratif, vol. 10, no. 1, hlm. 55-62, 2014. 